\title{
EFFECTS OF DISRUPTIVE SELECTION IX: LOW SELECTION INTENSITY
}

\author{
J. B. GIBSON and J. M. THODAY \\ Deportment of Genetics, University of Combridge
}

Received 27.ix.63

\section{INTRODUCTION}

IN the papers so far published in this series it has been shown that disruptive selection can have profound effects extending to the establishment of polymorphisms and the isolation of parts of a population from one another. In the earlier selection experiments (Thoday, I959, I960; Thoday and Boam, I959; and Millicent and Thoday, I 96 I) selection intensities were high, 5 per cent. of the individuals assayed being chosen for breeding in any generation. In later experiments (Thoday and Boam, I961; Thoday and Gibson, 1962; Gibson and Thoday, 1963), results at least as striking were obtained with reduced selection intensities, 20 per cent. of the individuals assayed being used for breeding. However, even these reduced selection intensities may be regarded as high, and it seemed worth while to make a test of the efficacy of disruptive selection at a much lower selection intensity. The results of such a test are reported here.

\section{MATERIAL AND METHODS}

So that the results should be as comparable as possible with one of our higher selection intensity experiments, we chose to repeat the experiment reported by Gibson and Thoday ( 1963 ) using the same Drosophila melanogaster base stock " Southacre", the same "quasi-random" mating system and the same population size, lowering the selection intensity simply by reducing the size of the sample of flies assayed from each culture.

Four 4-pair cultures of the stock were set up, and 8 flies of each sex from each culture were assayed for sternopleural chaeta number. From the resulting 32 females the 8 with highest and the 8 with lowest chaeta number were chosen for further breeding without bias in relation to their cultures of origin. The 8 highest and lowest males were likewise selected. The resulting flies were then set up in 4 4-pair cultures again. The first culture contained 4 high females with 4 high males, the second 4 high females with 4 low males, the third 4 low females with 4 high males and the fourth 4 low females with 4 low males. The process was repeated each generation.

This procedure is identical with that used by Gibson and Thoday (1963) except that they assayed 20 flies of each sex from each culture in each generation. They therefore selected 32 flies from a total sample of 160 , or 20 per cent. of the flies assayed. In the present experiment the 32 flies are selected from a total sample of 64 so that 50 per cent. of the flies assayed are used for further breeding.

\section{RESULTS}

Fig. I shows the mean chaeta number for the four cultures of the line for each generation. The High $\times$ High and Low $\times$ Low cultures 


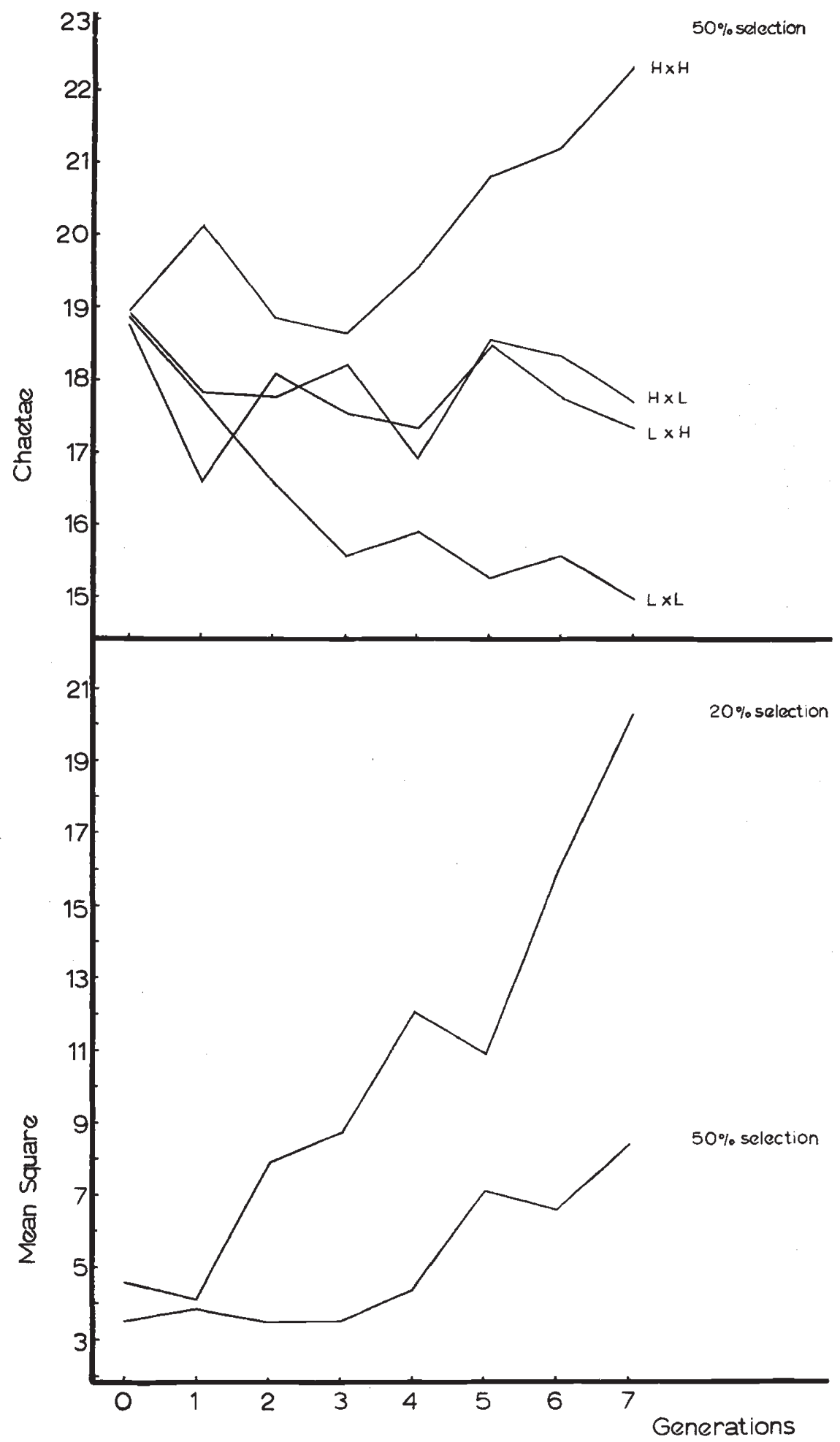

Fig. 1.-Upper graph: The mean chaeta numbers of each of the four cultures at each generation.

Lower graph: The total phenotypic variance of chaeta number in the experimental line $(50 \%$ selection), and in line $\mathrm{D}$ of Gibson and Thoday, 1963 . 
diverged quite rapidly from the "Hybrid" culture means. Also illustrated in this figure are the overall variances of chaeta-number in the line, and for comparison the variances obtained by Gibson and Thoday (1963) with their higher selection intensity line. The variance

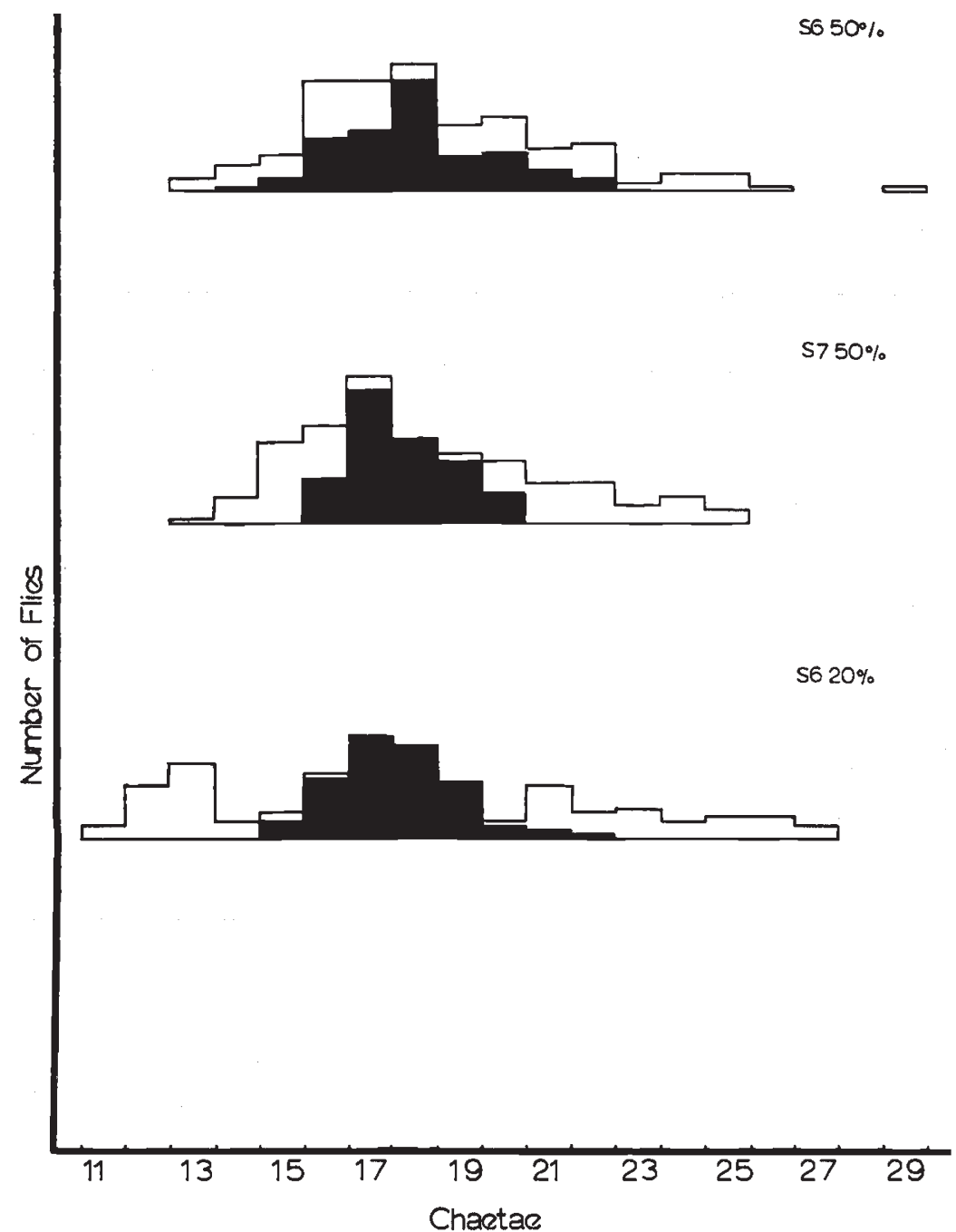

FIG. 2.-Chaeta number distributions at generations 6 and 7 and at generation 6 of Gibson and Thoday's (1963) D line. The area in black is obtained from the $\mathrm{H} \times \mathrm{L}$ and $\mathrm{L} \times \mathrm{H}$ cultures.

of the present line rose from about 3.5 to about $8 \cdot 5$; that in the earlier line, in the same number of generations, from 4.5 to 20.5 (that is about three times as much).

Fig. 2 shows the distributions of chaeta-number obtained in the last two generations of selection, based on the augmented sample size (20 of each sex from each culture), together with the comparable 
distribution curve for S6 of Gibson and Thoday's (1963) line. The figure shows the extent to which the High $\times$ High and Low $\times$ Low progenies differ from the hybrid culture progenies, and how the distributions compare with that for the earlier line. S6 was chosen to represent the earlier line for that was the last generation in which any flies were selected from the $\mathrm{H} \times \mathrm{L}$ or $\mathrm{L} \times \mathrm{H}$ cultures (see Gibson and Thoday, r963).

TABLE I

The cultures from which the selected fies came in each generation. The "isolation index" was obtained by adding the high fies selected from the $H \times H$ culture to the low fies selected from the $L \times L$ culture and representing them as a proportion of the total $3^{2}$ fies selected

\begin{tabular}{|c|c|c|c|c|c|c|c|c|c|c|c|c|c|c|}
\hline & & \multicolumn{13}{|c|}{ Generations } \\
\hline \multicolumn{2}{|c|}{ Culture } & \multicolumn{2}{|l|}{$\mathrm{SI}_{\mathrm{I}}$} & \multicolumn{2}{|c|}{$\mathrm{S}_{2}$} & \multicolumn{2}{|c|}{$S_{3}$} & \multicolumn{2}{|c|}{$\mathrm{S}_{4}$} & \multicolumn{2}{|c|}{$\mathrm{S}_{5}$} & \multicolumn{2}{|c|}{ S6 } & $s_{7} *$ \\
\hline & & $\mathbf{H}$ & & & $\mathrm{L}$ & $\mathrm{H}$ & $\mathrm{L}$ & H & & $\mathbf{H}$ & & $\mathbf{H}$ & & H L \\
\hline $\mathbf{H} \times \mathbf{H}$ & $\begin{array}{l}9 \\
0 \\
0\end{array}$ & 4 & $\begin{array}{l}. . \\
\cdots\end{array}$ & $\begin{array}{l}3 \\
4\end{array}$ & $\begin{array}{l}\cdots \\
\cdots\end{array}$ & $\begin{array}{l}4 \\
3\end{array}$ & $\begin{array}{l}\ldots \\
\cdots\end{array}$ & $\begin{array}{l}6 \\
6\end{array}$ & $\begin{array}{l}\ldots \\
\ldots\end{array}$ & $\begin{array}{l}6 \\
3\end{array}$ & $\ldots$ & $\begin{array}{l}7 \\
7\end{array}$ & $\begin{array}{l}\ldots \\
\ldots\end{array}$ & $\begin{array}{ll}8 & \ldots \\
8 & \ldots\end{array}$ \\
\hline $\mathrm{H} \times \mathrm{L}$ & $\begin{array}{l}q \\
0 \\
0\end{array}$ & I & $\begin{array}{l}2 \\
1\end{array}$ & $\begin{array}{l}3 \\
\mathrm{I}\end{array}$ & $\begin{array}{l}1 \\
3\end{array}$ & $\begin{array}{l}3 \\
3\end{array}$ & I & $\begin{array}{l}2 \\
\cdots\end{array}$ & $\begin{array}{l}2 \\
2\end{array}$ & 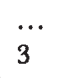 & $\begin{array}{l}\text { I } \\
\text { I }\end{array}$ & $\begin{array}{l}\text { I } \\
\ldots\end{array}$ & $\begin{array}{l}\ldots \\
\cdots\end{array}$ & $\begin{array}{cc}\ldots & \ldots \\
\ldots & \text { I }\end{array}$ \\
\hline $\mathrm{L} \times \mathrm{H}$ & $\begin{array}{l}\text { 웅 } \\
\text { d }\end{array}$ & $\begin{array}{l}\text { I } \\
\ldots\end{array}$ & & $\begin{array}{l}2 \\
2\end{array}$ & $\begin{array}{l}2 \\
1\end{array}$ & & $\begin{array}{l}1 \\
2\end{array}$ & $\begin{array}{l}\ldots \\
2\end{array}$ & $\begin{array}{l}2 \\
2\end{array}$ & $\begin{array}{l}2 \\
2\end{array}$ & $\begin{array}{r}\mathrm{I} \\
\ldots\end{array}$ & I. & I & $\begin{array}{cc}\ldots & 1 \\
\cdots & \ldots\end{array}$ \\
\hline $\mathrm{L} \times \mathbf{L}$ & $\begin{array}{l}q \\
0 \\
0\end{array}$ & $\begin{array}{l}2 \\
1\end{array}$ & $\begin{array}{l}3 \\
1\end{array}$ & I & $\begin{array}{l}5 \\
4\end{array}$ & $\begin{array}{l}\ldots \\
\cdots\end{array}$ & $\begin{array}{l}7 \\
5\end{array}$ & $\begin{array}{l}\ldots \\
\cdots\end{array}$ & $\begin{array}{l}4 \\
4\end{array}$ & $\begin{array}{l}\ldots \\
\ldots\end{array}$ & $\begin{array}{l}6 \\
7\end{array}$ & $\begin{array}{l}\ldots \\
\cdots\end{array}$ & $\begin{array}{l}7 \\
7\end{array}$ & $\begin{array}{ll}\ldots & 7 \\
\cdots & 7\end{array}$ \\
\hline Isolatior & & & $\frac{14}{32}$ & & $\frac{16}{32}$ & & $\frac{19}{3^{2}}$ & & $\frac{20}{3^{2}}$ & & $\frac{22}{32}$ & $\frac{28}{32}$ & $\frac{8}{2}$ & $\frac{30}{3^{2}}$ \\
\hline
\end{tabular}

* The flies that would have been used had the line been continued.

After S6, Gibson and Thoday's higher selection intensity line was effectively split into two for all the selected High chaeta number flies thereafter came from the High $\times$ High culture and all the Low chaeta number flies came from the Low $\times$ Low culture. Table 1 shows to what extent similar results occurred in the new line, for it lists the cultures from which the selected flies came.

It will be seen that by $\mathrm{S} 6$, almost all the selected high chaeta number flies came from the High $\times$ High cultures: in fact almost all the flies assayed from this culture were selected. Likewise the selected low chaeta number flies were almost all from the Low $\times$ Low culture and almost all the flies assayed from this culture were selected. This clearly was the end point of the experiment for the classes of culture 
had now become sufficiently distinct for selection intensity to be reduced almost to the limit implicit in the design of the experiment. This design is such that, since the sample assayed is made to comprise $5^{\circ}$ per cent. from the hybrid cultures, there can be no further selection beyond the point where the selected flies all come from the non-hybrid cultures. Hence the termination of the line at $\mathrm{S}_{7}$.

\section{DISCUSSION}

The relevance of the results of artificial selection experiments to interpretation of the possibilities in nature is often questioned on a number of grounds. Among these is the objection that artificial selection experiments involve very high selection pressures.

In the experiment described in this paper, the intensity of selection was reduced to a level as low as the experimental mating system permitted. The use of this lower selection intensity clearly had no qualitative effect upon the results of the experiments. Precisely the same kinds of things happened as in the comparable experiment of Gibson and Thoday (1963) in which higher selection intensities were used in the same way on the same material. Variance increased, and gene flow between the two selected types in the population decreased to a low level. Only the rates of response differed, and the ultimate level of response was not so great since the design of the experiment was such that effective selection intensity became less as selection was successful. The results clearly indicate that disruptive selection of relatively low intensity may be expected to have important effects on the genetic diversity of natural populations.

\section{SUMMARY}

I. A quasi-random mating disruptive selection experiment was run using low selection intensity for sternopleural chaeta number. Fifty per cent. of the flies assayed were selected as parents in each generation.

2. Variance increased and gene flow between the two extreme components of the population was rapidly reduced to a low level.

3. The results were essentially the same as in a comparable experiment using higher selection intensities suggesting that disruptive selection of relatively low intensity may be expected to have important effects in nature.

\section{REFERENCES}

GIBSON, J. B., AND THODAY, J. M. 1963. Effects of disruptive selection. VIII. Imposed quasi-random mating. Heredity, $18,5 \mathrm{I} 3-524$.

Millicent, E., AND thodAY, J. M. 196r. Effects of disruptive selection. IV. Gene flow and divergence. Heredity, $16,199-217$.

ThodAy, J. м. 1959. Effects of disruptive selection. I. Genetic flexibility. Heredity, $13,187-204$. 
Thoday, J. M. 196o. Effects of disruptive selection. III. Coupling and repulsion. Heredity, 14, 35-49.

THODAy, J. M., AND вOAM, т. в. I959. Effects of disruptive selection. II. Polymorphism and divergence without isolation. Heredity, 13, 205-2 I8.

THODAY, J. M., AND воAм, T. в. I96I. Effects of disruptive selection. V. Quasirandom mating. Heredity, $16,219-223$.

THODAY, J. M., AND GIBSON, J. B. 1962 . Isolation by disruptive selection. Nature, I93, I I 64-I I 66 . 